The architecture of the disaster

\author{
Teresa Stoppani \\ University of Greenwich \\ London
}

Teresa Stoppani

tstoppani@gmail.com

t.stoppani@gre.ac.uk 


\section{Teresa Stoppani}

\section{The architecture of the disaster}

The artificial disaster - the violent destruction of the body of architecture by an intentional and planned act - affects architecture in its physical presence as well as in its strategic and symbolic role. Yet, the symbolic role of architecture is not erased by the disaster, but reconfirmed and emphasized by negation. At work on the physical body and on the symbolic nature of architecture, the artificial disaster affects also architecture's exterior relations - of inhabitation and use, of history and signification. At the same time, the artificial disaster challenges also the nature of architecture as a discipline, questioning not only its role in the specific circumstances - what is architecture to do? - but also its very nature: what is it that architecture does?

Within the possible responses in architecture emerges the possibility of silence, that is, the project of the silence of architecture as an act of design. In the background of this argument are the key notions of 'silence' and 'impossibility' suggested by Maurice Blanchot in The Writing of the Disaster (Blanchot, 1995). Blanchot's text in fragments takes on the most difficult task of writing: to acknowledge, describe and explain what is not possible. Blanchot's writing (or non-writing) is concerned more or less implicitly with the writing of the disaster of the Nazi concentration camps, but his considerations remain valid whenever the issues of disaster and the writing of it are approached. In her introduction to Blanchot's book, Ann Smock explains that

'the writing of the disaster' means not simply the process whereby something called the disaster is written - communicated, attested to, or prophesized. It also means the writing done by the disaster - by the disaster that ruins books and wrecks language. 'The writing of the disaster' ... liquidates writing ... . [It is] the erasure of whatever it is that by this writing is written, the effacement of lines that cannot have been drawn if not by the stroke that now deletes them. (Ann Smock, in Blanchot, 1995, p. ix) 
If this idea is transposed to architecture, a possible redefinition of the project emerges. The architecture of the disaster is the work of the disaster on the architectural body; it is the use by the disaster of the symbolic of architecture; it is also the appropriation by disaster of architecture as its representation. The architecture of the disaster then is not only the representation of the disaster or the reaction to it. The architecture of the disaster is the impossibility for the architectural project to remain unchanged by the disaster. It is at the same time the impossibility to respond by reaction, and the need to respond by redefining itself, its role, its rules and its representations.

\section{The planning of the disaster}

The act of war, the terrorist attack and the systematic razing that affect architecture, act on it from the outside, according to logics that are 'other' to architecture. Beyond the physical effects of destruction of the building as shelter and container, what is affected of architecture is its twofold non-built dimension. On one hand the artificial disaster attacks what architecture represents and stands for - social and political systems, religious values, economic systems, financial assets, etc. Architecture's symbolic dimension, that is, has to be recognized in order to be targeted, and the physical attack on architecture confirms and indeed reinforces its symbolic dimension. On the other hand the artificial disaster indirectly affects architecture as a discipline and a language, beyond the immediate demolition, obliteration, and erasure of its physical body. The artificial disaster belongs to an unknown project that architecture cannot incorporate. This disaster is the impossible other of architecture, an incompatible event that architecture cannot include, and to which it can only react with its own tools - mapping, drawing, project (and this includes the possibility of silence).

The man-devised and produced disaster brings onto architecture the destructive suddenness of forces that operate against it with an intensity and a speed that are different from those of architecture. The artificial disaster can be read as 'an other' project, whose 
finality is different from that of architecture: although it acts in space and on space, its finality is not form. The artificial disaster reveals in an extreme way the exposure of architecture to other forces that affect the environment and that, like architecture, determine the making of space. The violent orchestrated event in space is a sudden and disruptive actualization of other forces (social, political, economical) that contribute to the shaping of the environment.

The purpose of the artificial disaster is not architectural. Its finality is not the destruction of architecture. More than a collateral damage, architecture becomes its medium. Here resides the crucial difference between the project of architecture and the project of the disaster: physical buildings, their forms and their significations are affected by both projects, but the purposes are different. The artificial disaster is not a project of making or altering space for its inhabitation (both physical and symbolical); it produces formal effects, but its concerns are not formal or aesthetic. The planned attack of architecture does not express an aesthetic judgment on architecture; its judgment is political and ideological. Architecture is attacked for what it stands for, and not for what it is. The artificial disaster, that is, uses architecture as a physical implement, a symbolic device, and a medium of representation. Using architecture instrumentally, the dramatic destructive event exposes and confirms the openness of architecture as a 'weak' discipline that participates and operates in a reality that remains informed and largely defined by the non architectural.

As examples of artificial disasters, I consider here acts of war - be they called war, humanitarian intervention, intelligent bombing, act of terrorism, or State coercive diplomacy, which invest architecture as symbolic or opportunity target with a 'design' that is external to it.

Like architecture, the disastrous event produced by war or terrorism is carefully planned in space and in time - choreographed. In architecture, design and planning are concerned with space definition and form making. Architecture and the city develop and are implemented slowly, with the slow pace of construction. The destruction inflicted by the 
disaster has to do instead with the undoing of the form of planned structures and orders be they societal, urban, economic or national. Acting on architecture, the destructive event exposes the embedded weaknesses of its built system, while at once suddenly introducing a different way of reading space.

Beyond the effects of the disaster on architecture as a sudden undoing of its form, the question remains of architecture's response to it, that is, how the discipline of architecture is changed by the planned destructive event. Here I look at some architectural projects which work with the energy released by the planned disastrous event, addressing and exploring its effects not on the immediacy of the singular building or environment, but on the practice of architecture at large. Architecture's artificial disaster is not intended here as the accidental collapse or the staged demolition of a structure, which are both intrinsically part of the architectural project - either as its failure or as its extension. Exterior to architecture, the intentionality of the artificial disaster resides outside architecture. While the planned physical aggression on architecture has no formal concerns, it employs the forms of architecture, using architecture as a representation of its project. Architecture becomes a graphic representation of the artificial disaster, the body inscribed by a project that is other from itself, and what is opened up and challenged is the representation of architecture. The artificial disaster challenges both the role of representation in architecture (how architecture is represented, and the relationship between architectural representation and the architectural project) and representation by architecture (how architecture is appropriated as representation by a project other than itself). The aggression of the artificial disaster is thus perpetrated not only on the body of architecture, but also on its disciplinary corpus. A dilemma opens up here for architecture, as to the necessity of redefining its role in relation to the project of the disaster. The following architectural responses to the project of the artificial disaster are attempts to re-appropriate architecture and its strategies, producing a distance from the disaster that enables the redefinition of the architectural project. Among these strategies is also the silence of architecture, or silence as a project. 


\section{The mapping of the disaster (Urbicide)}

In Sarajevo, between May 1992 and October 1993, the Architects Association Das-Sabih documented the systematic destruction of the city with photographs, maps, video footage, audio and written accounts. On 16 March 1994 five members of Das-Sabih escaped from the city under siege with the documentary materials that would became WararchitectureSarajevo: a Wounded City, a travelling multimedia exhibition illustrating the destruction of the architecture of Sarajevo. ii Urbicide Sarajevo, A Wararchitecture Dossier (1994), the dossier that accompanied the exhibition, documented the systematic destruction of the city's monuments and buildings. The dossier is dry and systematic, a survey of damages to building and structures organized in chronological/stylistic order according to four architectural periods. ${ }^{\text {iii }}$ The scale of the disaster is measured in details, hit by hit, fire by fire, grenade by grenade. Each damage is photographically documented, described in lists that read like of inverted architectural specification documents, and recorded on cadastral maps and city maps. Accurate but still in the making, these documents constitute an open archive, an ongoing survey that, although it could serve as a tool for detailed reconstruction plans, is offered in itself, as it is, as a silent witness.

Painful and painstakingly precise, photos, mappings and words document a siege perpetrated in time. War here becomes as slow as architecture and its making. The destruction proceeds systematically but slowly, piecemeal, in a time so long that, as in old photographs, human presence is erased and only its traces remain in the objects that are left behind. Building by building, according to the chronological order of their making rather than the time of their destruction, this systematic account of damages does not count deaths. There are no people in this documentation, no human lives lost, no blood, and the photos are significantly published in black and white. The emphasis thus falls onto the forms, their incompleteness and unravelling. Mute, scarred, burnt, the buildings or what remains of them carry the loss and bear witness to the atrocity. Weak and vulnerable, structurally damaged, collapsed, they become (or remain, even more than before) symbols. But the symbolic is so diffuse in this Sarajevo that it becomes an urban tissue, beyond the single architectural object. The diffused but discontinuous destruction 
establishes a new disquieting continuity, for the documentation of which the photograph remains insufficient. Photography here is not only the celebration of the damaged fragment or the documentation of the lost detail, but it works only in the plural, as a series.

The photo reportage is accompanied by the mapping of the damages. Detailed, annotated with accuracy, the maps are even more powerful than the photographs, and enter both public buildings and private lives with the precision of a surgical knife. Like the archive that they accompany, these maps are unfinished, in the making as the buildings are undone. And while the physical built city will heal most of its wounds, bear the scars but grow new tissue in them, these maps (and photographs) are charged with the role of defining the moment of the making of the disaster. Beyond mere documentation, this survey, characterized by the precision of its data and the systematic organization of its details against the historical and architectural background of the city, becomes a critical project. The documentation of the damages could have provided a chronological account by moments of destruction, or a neighborhood-by-neighborhood spatial description. It chooses instead to place itself within the discipline of architecture, providing a historical background to what of the body of the city has been erased. It also chooses to operate in space-time, using the conventional tools of architectural and urban representation (the photo, the plan, the text) to produce an archive in the making that remains open to future strategies of intervention. The materials are thus presented in a loose-leaf folio whose order remains re-combinable.

The maps represent the synthetic moment of this process. While photos can be added to photos, and words to the list of damages, the map remains subject to constant reworking, and its internal relationships are constantly renegotiated. The map represents at once the pre-existing context and the formal effect of the damage; it also documents the production of the photographic documentation. Open and instrumental, it operates at the immediate level of historical documentation, and it also offers basic information for reconstruction projects. At the same time this mapping establishes a new way to document (but also to draw, make, legislate) the making of urban space. The map is also 
the site for the representation of the work of the disaster, as it records monuments and elements of the city that now emerge for their damages rather than for their historical or architectural relevance. Here the disaster produces, and the map records, a different logic that establishes new categories, blind to aesthetic and stylistic criteria and also to the utilitarian and infrastructural reasons of architecture. The 'mapping of the disaster' establishes new relationships and new proximities in the urban space. The combination of the survey at the scale of the city with the micro-level detail of the damages allows a reading of the city as an organic, mortally wounded but still alive body. The pain of the wounds seems even bigger because it is so diffuse, so extensive, and yet so precisely and clinically articulated: 'direct hit, direct hit in the roof, direct hit in the façade, roof damage, partly burnt, completely burnt down, completely destroyed' (Association of Architects DAS-SABIH Sarajevo, 1994) are the items in this legend of war.

What is this work then? How does it challenge architecture and how does it invest it with roles old and new? It is a document, a survey, an archive, a tour guide, a plan for reconstruction; or in itself a monument, a celebration, a book of mute and yet loud account. The description of the damages is written and mapped, and the loose leaf format of the dossier allows for the mapping of damages to be organized topographically, by damage, by style, by priority of reconstruction, by amount of damages, by degree of destruction, etc. This multi map is openly structured to be as heterogeneous and as pluralistic as the culture of Sarajevo itself. The meaning of the operation is, of course, political. $^{\mathrm{v}}$

This is also a project that chooses not to design. It does not offer sets of building instructions, it does not devise spatial arrangements. It organizes instead relations of times, and defines the silence as architectural pause.

How many efforts are required in order not to write - in order that, writing, I not write, in spite of everything. ... There is nothing negative in 'not to write'; it is intensity without mastery, without sovereignty, the obsessiveness of the utterly passive. (Blanchot, 1995, p. 11) 
Blanchot's remarks are relevant here to consider the architectural and urban, cultural and political significance of the Urbicide Sarajevo project. The tracing of lines and the marking of marks of this project are architecture's writing - this too is a project. On one hand the project declares the insufficiency and impossibility of bearing witness to the disaster, of producing of it an exhaustive account. Not only will this document (the map or the archive) always be in the making (incomplete); it will also be always insufficient to the object of its representation. On the other hand the recording of the disaster takes place in and on the city itself: the buildings and their remains become the inscription (the tracing) of the war, a three-dimensional rendering of the horror. But above all Urbicide Sarajevo is a project for the distance it produces, for its 'editing out'. The potent 'writing' of this project is its silence - what it does not say, what it does not show. The silence is in the buildings it catalogues, and it is, also, in the project's silence about human lives, sufferance and loss. There is also, in this silence and in the incompleteness of this project, a fundamental optimism. The catalogue of the wounded architectures of the city becomes a collective monument of national identification that celebrates differences, heterogeneity and coexistence as a strategy for 'lively' planning.

\section{3-95. The project of the disaster (Wararchitecture)}

Architecture and war are not incompatible.

Architecture is war. War is architecture.

I am at war with my time, with history, with all authority

That resides in fixed and frightening forms.

(Woods, 1993, p. 1)

For American architect Lebbeus Woods, "Building is by its very nature an aggressive, even warlike act. ... Buildings are objects that disrupt existing landscapes."(Woods, 1995 , p. 50). War then is not an external agent that acts on architecture, but it brings to paradoxical extremes the violence that is intrinsic to architecture. The violence of war 
questions architecture's performance of rituals, and exposes the conflictual relationship between architecture and action.

While the Urbicide Sarajevo documentation is presented around the world, Woods produces his War and Architecture project, which addresses the conditions of Sarajevo after the siege of 1992-96. For Woods cities devastated by the disaster should not restore their buildings and erase the evidence of the destruction, but maintain and express the traces of their wounds. The rebuilt city should acknowledge the damage and construct around it a 'new tissue' of 'scabs', 'scars' and 'insertions' (these the names of Woods's proposed designs for Sarajevo) grafted on its wounded fabric and buildings. While the architects of Das-Sabih document the writing of the disaster on Sarajevo, Woods writes the disaster itself: he assumes its doing (or undoing) to turn it into a design project. Here architecture and war are no longer mutually exclusive but co-habit in the same cityscape where destruction and remaking coexist.

Architecture's possibility of survival in a context of random destruction lies in its fluidity and adaptability - an architecture that operates by moves rather than rules: quick, shifty, adaptable and able to make do with the precarious conditions and materials it finds itself in. This implies a work that operates within the given, and is characterized not by the forms it produces but by the moves that generate it: different results, formal outcomes, regimes of ownership and occupations are determined by the specificity of the situation. The architectural forms produced are always unpredictable, constantly changing, and always incorporating different times and durations (the sudden time of the explosion, the quick time of collapse, the slow or broken time of a makeshift construction). This design strategy seems to assimilate contemporary strategies of war, the urban raid and the guerrilla rather than the frontal array and confrontation of regular armies. This architecture incorporates war in its modus operandi, at the level of the single building as well as in the system of its interconnections. Wood's project is not only formal: its forms are the products of a strategy of occupation and connection, and correspond to a proposed new regime of ownership. What seems at first exclusively a figural provocation, proposes 
in fact a political and social strategy of survival that employs architecture without severing its representation from its urban and social role.

Woods' project embraces and inhabits the disaster as one of its tools, in a too easy and too obvious translation of its effects. Architecture here becomes the formal language for the concretion of the disaster, thus reducing any tension and stifling any possibility of change. Woods' projects 'write' the disaster too soon, too quickly, too literally, without constructing any distance from it. The forces of the disaster are frozen in the time (duration) and in the forms (building) of architecture, and the forces of architecture are subjected to the rules of a project whose finality is other from form making. In Woods' proposals the disaster is literally allowed to 'write' in architectural form. Woods claims to withdraw authorship and let forms emerge for an 'architecture built as though it had never been drawn' (Woods, 1993, p. 36), but his project operates in fact through a seductive representation that uses the architect's own signature graphics, rather than developing the proclaimed author-less process for dynamic design. The proposed images remain in fact a device for the application of a personal congenial language that embraces the disaster in order to express itself.

War and Architecture claims to propose a dynamic self-adjusting system that is not concerned with the formal but is conditioned and generated by its material possibilities, but this strategy finds expression in the frozen form of an aestheticized personal architectural language that refers to a personal imaginary (and imagery). Two problems arise here. The precariousness of the situation does not eliminate the problem of the project - architecture. Danger, scarcity of resources and constantly changing external conditions do not 'free' construction from the demands of architecture. Beside and beyond the constraints and requirements of shelter, support and safety, the architectural project continues to offer formal solutions that exceed the basic needs of protection. The formal suggestions of Woods' project indeed instigate a critique of architecture, but this is limited to its formal expression.' His 'wararchitecture' offers the unsatisfactory and facile formal solution of an architecture that literally embraces and traces the forms of its antagonist. This is an architecture that solidifies the explosions, constructs the crater, fills 
in the gap using as a mould the formal effects produced by the act of war. Proposed here as a reaction to the disaster, this architecture in fact uses the forms produced by war, embracing a rhetoric of explosion and destruction that is obviously not indifferent to the formal appeals of the architecture of deconstruction. What remains unaddressed here is the possibility (and responsibility) for architecture to go beyond a formal strategy of given forms and propose instead a strategy of making form that affects and organizes space. The War and Architecture projects remain formal responses to the destructions of war that can only reproduce and re-inscribe the 'writing' of the disaster on the body on the city. Architecture's response remains figural rather than process oriented, and the agency of the project is left to the disaster.

\section{4-92. The violence of architecture (Fireworks and The Fall)}

1. There is no architecture without action, no architecture without events, no architecture without program.

2. By extension, there is no architecture without violence.

(Tschumi, 1994b, p. 121)

In the 1970s, working from 'inside' architecture but appropriating themes developed in philosophy, film and semiotics, Bernard Tschumi's provocatively proposes his definition of the intrinsic violence of architecture, aimed to emphasize the dynamic aspect of architecture. Action, explosion, destruction, and violence become in Tschumi's work both goals and mediums for the expression of an architectural project that refuses to privilege space and includes the event. In his project architecture is the ground where objects and man confront each other in tension, each operating according to a different logic. Each intrusion of the human body in the established order of architecture violates and at the same time animates a construct that would otherwise remain inert, and as such would not be architecture, but only its image. 
The violence on architecture that brings about its physical destruction is thus only the paroxystic manifestation of "the intensity of a relationship between individuals and their surrounding spaces" (Tschumi, 1994b, p. 122). But this relationship is not so straightforward. The presence and the movement of bodies in space constitute already an architectural act, in which "bodies carve all sorts of new and unexpected spaces, through fluid or erratic motions" (Tschumi, 1994b, p. 123). And while bodies produce disturbances in the architectural order, architecture inflicts control and restriction onto the body in motion, and is in itself "violence ritualized" (Tschumi, 1994b, p. 125) that freezes and repeatedly re-stages the relationships between action and space. Codified architecture solidifies this relationship in a procedural prescription of iterated acts.

Tschumi's own work in architecture aims to operate between the violence that is already embedded and codified in architecture, and the violence of the body that disrupts the order of architecture. By deprogramming, by introducing the unexpected, by breaking away from the ritual that architecture solidifies, Tschumi's interventions question the relation of architecture to life, inhabitation and movement. Unusual or misplaced actions in architecture release the energy that is frozen in this relationship, and challenge the codification of architecture and its representations, revealing the transgression that is always already at play in architecture.

What Tschumi defines "programmatic violence", far from being metaphoric, intervenes not only on the architectural representation but also on the material structures of architecture, and indeed on actual human bodies. This violence "encompasses those uses, actions, events, and programs which, by accident or by design, are specifically evil and destructive. Among them are killing, internment and torture, which become slaughterhouses, concentration camps or torture chambers" (Tschumi, 1994b, p. 134). Tschumi does not seem to distinguish between accident and design of the violent act, and yet he concentrates mainly on actions that require not only an intentionality but also a project, a detailed strategy of implementation in space and time - a choreography. 
The Fireworks manifesto of 1974 (Tschumi, 1979, 4-5) in which Tschumi states that architecture should be built and burned just for pleasure, dissolves the solidity and permanence of architecture in an ephemeral choreography for a designed violent release of energy. Architecture is no longer a restrictive container or a constrictive frame for the event, but the designed event itself, and the energy released by architecture is translated and choreographed in a system of spatio-temporal organizations (the explosion of the fireworks) that are anticipated (designed) by a script and a set of drawings and notations. ${ }^{\text {vi }}$

In the same years when he is theorizing the violence of architecture and designing pyrotechnic explosions, Tschumi produces also the Manhattan Transcripts (1976-81), a series of critical theoretical projects that follow his period of active engagement in the urban context. In the Transcripts architecture is reconsidered in the context of the city, from which it is inseparable. It is in the city that architecture has to deal with phenomena that are out of its control, and these are often violent. The conventional representations of architecture are also challenged, as the Manhattan Transcripts project can only be expressed (transcribed) by the triad of 'space-event-movement', represented respectively by the drawing, the photograph and the diagram, always combined. In the Manhattan Transcripts "the idea of order is constantly questioned, challenged, pushed to the edge". (Tschumi, 1989, p. 176)

The Transcripts use extreme programs (homicide) and violent actions that exceed the common notion of 'function' to separate it from both the architectural form and from social conventions. The four projects of the series dissect and explode the architectural discipline and the given orders of the city, in a crescendo that focuses on its in-between spaces, borders and limits. The Park, The Street, The Tower, and The Block become stages and participants for, respectively, a murder, a chase, a suicide, and a disruption of institutionalized structures.

The Block sets in motion five inner courtyards of a Manhattan block with a series of contradictory events and spaces - 'programmatic impossibilities' that progressively transgress and eventually explode their architectural spaces. The Tower (The Fall) offers 
a reading by "intrusion" in the vertical layering of the Manhattan skyscraper, performed through the fatal fall of an "inmate" through the tower's vertical stack of self-same cells. The fall of the body produces an altered perception of the spaces and defies their distinction determined by use (home, office, prison, asylum), and while the tower is represented by conventional architectural sections, the movement of the falling body 'reads' them as a filmic vertical sequence of intruded horizontal layers (floors).

The Transcripts question the discipline from within, while proposing references and transdisciplinary openings for a redefinition of architecture. They constitute a moment of critical re-elaboration from which Tschumi will take his projects out of the printed page and the gallery and into the physical city. The Transcripts remain a theoretical architectural provocation, but they are also 'placed' in Manhattan, and use the repetitions and superpositions, but also the exceptions and conflicts, contained in its orthogonal grid. Manhattan offers also a negotiable intertext, in which urban structure and forms are already ruthlessly determined by forces external to architecture.

Ten years after the first performance of Tschumi's Fireworks and twenty years after his theorization of violence in architecture and his projects of disruptive transgression, the events of September 11, 2001 in Manhattan introduced another type of violence, different not only in magnitude and horror, but in its nature. Here the programmatic violence was not produced by architecture, but by carefully planned external forces violently acting on it. Tschumi's projects of individual free fall and coordinated collective explosion of architecture now read as uncanny prophecies which were far surpassed by reality.

Beyond the devastating dimension of the human tragedy, the disaster of 9/11 raised also questions of architecture, and an architectural reading of 9/11 could possibly consider it as a massive scale architectural experiment. But one fundamental mistake would occur here. Tschumi's theoretical works from the 1970s are investigations on the forms and the languages of architecture, and a momentary move away from explicit political and social concerns. Political and social concerns, though, are always embedded in architecture, and even more so in the case of $9 / 11$. It is important then not to confuse an architectural experiment and provocation with the destruction of a built architecture and the huge loss 
of human life attached to it. Architectural manifestos (Tschumi's advertisings), fireworks displays, urban narratives and their graphic representations in the form of "transcripts" are architectural projects even if they are not buildings, and even these theoretical architectures combine their formal concerns with the social and the political.

\section{1-02. The drawing of the disaster (Fireworks II)}

Bernard Tschumi had theorized the intervention of violence on architecture as a release of the violence of architecture itself, breaking the architectural object and its conventional forms of representation. Lebbeus Woods extended these themes beyond the relationship of use and form, addressing the relationship between architecture and the environment when paroxysmal events (war, earthquake) question the form and the making of architecture. In 2001 the horrid test of these ideas came into being with the tragic events of 9/11 in Manhattan. Violence left the written pages and drawing boards and became real, physical. Sudden, unexpected, unconceivable in architecture, but precisely and carefully choreographed outside of it, the terrorist attacks on the towers of the World Trade Center seemed to enact in a terribly amplified nightmare Tschumi's architectural provocations - and they did it at a scale magnified in proportion, dimension, conflict, political significance, and human tragedy. The explosions here are not time-sequenced firework displays, but impacts of actual airline Boeings flown into the symbols of American global economical power. The deflagrations do not produce fragmented perspective views, but the actual destruction of buildings and lives. The leaps into the void are not simulated suicides used to measure the vertical order of architecture, but desperate determinations to control life's last seconds. Architecture is muted, physically pulverized, stunned as a discourse. Then, beyond and beside the human tragedy, architecture too has to cope. The destruction triggers the questioning of the role, meanings, weaknesses and responsibilities of the discipline, from the ambition to verticality that has always characterized architecture, to the implication of moral issues of representation that invest it. 
While the general architectural debate concerns itself with the issue of the meaning and legitimacy of wanting to build higher and higher, with the problem of the aestheticization of the ruin, and with issues of memory, and site monumentalization and speculation, Belgian architect Lieven De Boeck produces a designed response to the events of 9/11 in Manhattan. His project Fireworks II, Le Bleu du Ciel - the title an obvious homage to Tschumi's homonymous project and to his Bataillean cultural references ${ }^{\text {viii }}$ - keeps its focus on the planning of the disaster as a choreographed architectural act. Here the disaster is re-appropriated graphically by architecture, its planning turned into architectural drawings, diagrams, legends and data sheets. After the events, De Boeck's work condenses the planning, the unfolding and the consequences of the attack in a series of architectural documents, reconstructing and reinterpreting the facts in architecture. The figurative (drawing of the explosions), the descriptive (architectural drawings of the buildings and the airplanes), the diagrammatic (flight paths and time lines) and the quantitative (times, distances, geographical coordinates, speeds, weights) are combined in a synthesis that employs different architectural media. Unlike the photographic and cartographic recordings of Urbicide Sarajevo, here the architectural project incorporates and represents also the planning and the tools of the attacks, before the unfolding of the events.

In this project violence on architecture, violence of architecture and violence as architecture converge in a dry and yet poignant account. The precise factual information of these drawings and diagrams is as silent and as powerful as the Urbicide Sarajevo mappings. Human life is once again absent from both the representation and the counting, but what is represented this time is not the objects (the buildings and their damage) but the event itself - the planning, the location and the realization of the action. De Boeck's project is a "ruthless" "personal reflection" on one of the most brutal terrorist actions at the start of $21^{\text {st }}$ century and "the most violent act of urbanism that the world has ever seen”. (Davidts, 2005, p. 242) But this personal reflection is a project, and as such it produces a distance. De Boeck analyzes the event "as an architectural enterprise, as an act that gains significance from an architectural point of view." (Davidts, 2005, p. 242) The site plan, flight positioning and data, coordinates and times, together with conventional 
architectural drawings - plans, sections and elevations - are used here to represent the project of the disaster.

Michael Sorkin has observed that the commemoration of the events of 9/11 introduces the need for measurement, that "the process of recovery would involve repeated mapping of the meanings not just of the site but of the very idea of site ... [of] fires still burning, the precise location of wreckage, the fallout of debris, the location of remains". (Sorkin, 2003, pp. 8-9) Even more morbidly, these measurements could include the mapping of all the bodies and body parts found on the site. (Libeskind, 2004, p. 50) But this is not what De Boeck is interested in. The measurement produced here is not that of the aftermath but that of the event itself. The exploded perspective view - or "afterview" (Davidts, 2005, p. 243) - of the deflagration, its shadows and thrust fragments goes beyond the possibilities of conventional architectural representation, and certainly beyond the possibility of building. The explosion - the event - becomes here part of the architecture that is represented. De Boeck reads the attack on the Twin Towers as an architectural performance. He even reminds us that the pilot who flew the first plane into the North Tower was an architect who had graduated in Cairo and had gone on to study urban planning and preservation at Hamburg TU.

What does this mean in the specifics of architecture? The extreme event exposes the complexities, limitations and conflicts that inhabit architecture, invested as it is by "other" systems of signification. Beyond the symbolism of a late modern international building complex that had come to represent the centre of global economic influence, the Twin Towers were also the icon of a myth of renewed birth and indomitable progress that is exclusively "New York". Superposed on these givens, De Boeck's attempt is specifically architectural: it re-appropriates the event to architecture, incorporating it in the project - the disaster as architecture. At the same time, it strips architecture of the added meanings that have accumulated on it, and returns the symbol-building to architecture. 
Tschumi's paper experiments of the 1970s are not referred to here as a chilling prophecy, but because they provide an architectural language that combines event, notation and drawing to "transcribe" and represent ("write" - in Blanchot's terms) the disaster. It is not the obvious similitude of the image of the suicidal fall that links De Boeck's project to Tschumi's Transcripts, but the appropriation of the event by architecture. The violence that invests architecture conflagrates in one moment all the roles - shelter, representation, symbolism, power - that it normally plays in day-to-day experience. Architectural representation - what architecture represents and how it represents - is also transformed.

\section{3-??. The silences of architecture (Ground Zero)}

In September 2002, as a response to the commercial plans proposed for the site of the World Trade Center by the Lower Manhattan Development Corporation, an international group of renowned architects present the results of a collaborative design effort for the Downtown Manhattan areas surrounding Ground Zero. The initiative, featured in the New York Times Magazine and curated by the paper's architecture critic Herbert Muschamp, addresses the problem of post-9/11 design as a wider architectural and urban issue. Architecture is called upon to implement the grand vision of the city with a design response to the project of the disaster. The piece proclaims: "Now is the time for New York to express its ambition through architecture and reclaim its place as a visionary city." (Muschamp, 2002, 45). The master plan proposes a general urban strategy encompassing a large area around Ground Zero as a collective project whose protagonists, structures envisioned by Zaha Hadid, Peter Eisenman, Rem Koolhaas, Rafael Viñoly and others, are lined up along a redesigned West Street. The twin towers appear here, devoid of design detail, shifted from their original position but equally big and imposing.

The two faceless towers find an architectural definition a few months later, in February 2003, when Daniel Libeskind unveils his 'Innovative Design Study’ competition-winning master plan for Ground Zero. Proposing a series of smaller towers that surround the much taller centrepiece of the 1,776-foot-high Freedom Tower, the scheme preserves the World 
Trade Center crater as a memorial site. The master plan, called "Memory Foundations", contains all the winning ingredients of a successful project for the site: the soaring monument (Freedom Tower), the foundation memorial (later designed by Arad and Walker), the celebration of human life (Park of Heroes), the remembrance of the event (tracing as re-enactment in the Wedge of Light), the cultural marker (Museum), and the economically enabling corollary development (surrounding commercial towers). The project reacts to the disaster with New Yorker brashness, energy and inspired vision, but in its cacophony of all-pleasing solutions, architecturally it says nothing. It forgets to search for answers beyond the rhetoric of the tragedy and the vitalistic reaction of the city. It fails to address the problem in terms of the issues it challenges and the responsibilities it demands from architecture. The proposal becomes an optimistic celebration of the event and its memory, and in its presentation the architect reduces the exhibition to spectacle, and the spectacle to gossip. What lacks in this all-pleasing design is the critical and ideological role that is demanded of architecture, always, and especially after $9 / 11$.

The winning master plan and the publicity that surrounds it trigger the indignant reactions of many voices of world architecture culture, ${ }^{\text {xiii }}$ who see the project as a rather conventional and celebratory formal solution. Yet, the process of its realization unintentionally opens up a possibility to identify a new role for architecture. For Alicia Imperiale, Libeskind's project discovers a social and political dimension of architecture that goes beyond the scale of the city or the metropolis (Imperiale, 2003, 39-43). The issues at stake in the project, its scale and social dimension, are global and internationally mediated rather that local, and architecture, rather than focusing on a static and representational form, can be deployed as a strategy - a trigger. The strength of this project then does not reside in its rhetorical image, nor in its questionable public relations backing, but in the possibility to read it as a "political agent" that does not produce form but "the promise of form". "The scheme could be phased over many years and never fully completed. This in itself could be read as a subversive political act - architect as unbuilder." (Imperiale, 2003, 43)The pre-formal political agency that Imperiale identifies as a possibility of the master plan remains, in Libeskind's project, mostly accidental. 
Certainly the most direct and immediate effect produced by $9 / 11$ on architecture was that it exploded the crisis of the skyscraper and started a process of revision of its typology and structure. But even in this respect the focus of Libeskind's proposal remains the formal definition of the architectural object, and its iconic presence in the city.

Beyond the immediate reactions that echoed or traced the writing produced by the disaster, the discipline of architecture has still to critically respond to $9 / 11$. What remains to be called for is a new task for architecture, and this could perhaps be the definition of its silence. Far from the silencing of critical architecture produced by Libeskind's cacophony, and from the pornographic awe for the debris and the twisted metal expressed by some during the aftermath of the disaster ${ }^{\mathrm{xv}}$ architecture can propose a different kind of silence. Silence as architectural design and planning response and as a "promise of form" can be conceived and articulated.

Michael Sorkin attempted to do this in the two years that followed 9/11, developing his reaction to the disaster in architecture through a series of writings and projects (Sorkin, 2003). The projects went formally in full circle, but remained conceptually and critically consistent, as did his writings in support of a social and political engagement that would not concentrate exclusively on the immediate physical site of the disaster. Michael Sorkin Studio's early design proposals ranged from a comprehensive redistribution and redevelopment plan for Lower Manhattan (November 2001), to a series of projects for the World Trade Center site that gradually dissolve the architectural form - from a protective berm around the craters, to a huge geodesic dome, to its opening up into a group of torqued towers, to their disappearance - as a critical act that remained firmly based on design, but focused more and more on the devising of strategies rather than on the definition of closed forms. In the end the Back to Zero project (April 2003) returned the site to the city as an open public park that paid tribute to a series of European urban squares but operated like that "synthetic Arcadian Carpet" (Koolhaas, 1994, p. 23) that is Manhattan's Central Park.

Ground Zero in its voided condition belongs to a family of great spaces in both its scale and proportion. ... there can be no stronger repository of meaning than the 
space of its void. Grandeur, dignity, and universal access best mark both tragedy and renewal. Nothing need be built there. (Sorkin, 2003, p. 137)

This is no symbolical defeatist gesture in which the project renounces design. Responding to an architecture that has rushed a reaction of reconstruction and verticalism to the disaster and has left unanswered its many questions, Sorkin proposes an architecture that can be formally silent but socially relevant. "Build nothing" is not "do nothing", and it addresses the political agency of an architecture that aims to be globally and internationally effective beyond its formal resolution.

Perhaps this is the site for reimagining architecture, not from the position of either power or paranoia but from a sense of humanity and compassion. Perhaps ... this is a site not to be rebuilt. ... Perhaps this is a scar that should simply be left. Perhaps the billions should be spent improving transportation and building in neglected parts of the city [and] of the world. (Sorkin, 2003, p. 23)

Architecture is yet to fully explore its possible "writing" of the disaster and its response to it. Sorkin's Back to Zero project called for an architectural silence capable of (re)appropriating the terrorists' symbolic appropriation of architectural space. Proposing architecture as a practice of social collective engagement, the project spoke up against the U.S. imperialism that (indirectly) had enabled that symbolic appropriation. Sorkin's "silent" project for Ground Zero would have been a constant reminder of the ghost presence of the event - not as a celebration of the ruin, but as a form of collective (public) re-use. The incongruous presence of its giant inexplicable, unprofitable void would have spoken of its exceptionality through its silence. 


\section{References}

Association of Architects DAS-SABIH Sarajevo (1994) Urbicide Sarajevo, A Wararchitecture Dossier. Ministere de l'Equipement, des Transports et du Tourisme, Direction de l'Architecture et de l'Urbanisme, France. A selection of images from the catalogue is available from: http://imaginarymuseum.org/MHV/PZImhv/UrbicideSarajevo.html. Retrieved February 28, 2010.

Blanchot, M. (1995). The writing of the disaster. Lincoln and London: University of Nebraska Press.

Davidts, W. 2005. Home call: a case in architectural storytelling. Reflections on the work of Lieven De Boeck'. In dlk (de loeiende koe) (Department of Architecture \& Urban Planning, University of Ghent) (9) 2:236-251. Quote from p. 242.

De Boeck, L. (2002). Fireworks II, Le Bleu du Ciel. In Book, p. 34. Available from http://www.lievendb.com/work.html. Retrieved February 28, 2010.

Imperiale, A. (2003). Fluid Alliances. Log: Observations on Architecture and the Contemporary City, 1, 39-43.

Muschamp H. (2002). Thinking big: a plan for Ground Zero and beyond. The New York Times Magazine, 8 September 2002, 46-58.

Koolhaas, R. (1994). Delirious New York. A retroactive manifesto for Manhattan. New York: The Monacelli Press.

Libeskind, D. (2004). Breaking ground. Adventures in life and architecture. London: John Murray.

Sorkin, M. (2003). Starting from zero. Reconstructing Downtown New York. New York and London: Routledge.

Stoppani, T. (2006). The reversible city: exhibition(ism), chorality and tenderness in Manhattan and Venice. In C. Lindner (Ed.), Urban Space and Cityscapes (pp. 155176). London: Routledge.

Tschumi, B. (1979). Architectural manifestos. London: Architectural Association. 
Tschumi, B. (1989). Parc de la Villette, Paris. In A. Papadakis, C. Cooke, \& A. Benjamin (Eds), Deconstruction (pp. 174-183). London: Academy Editions.

Tschumi, B. (1994a). The Manhattan transcripts. London: Academy Editions.

Tschumi, B. (1994b). Violence of architecture. In Tschumi, Bernard, Architecture and disjunction (pp. 121-137). Cambridge M.A.: M.I.T. Press.

Woods, L. (1993). War and architecture, Pamphlet Architecture, 15. New York: Princeton Architectural Press.

Woods, L. (1995). Everyday war. In P. Lang (Ed.), Mortal City (pp. 47-53). New York: Princeton Architectural Press.

Younge, G. (2003). Winning trade centre design stirs pride of New Yorkers. Libeskind's plans for Ground Zero will "bring back the life to lower Manhattan". The Guardian, 28 February 2003. Retrieved 28, February 2010, from http://www.guardian.co.uk/world/2003/feb/28/michaelbloomberg.september11.

\footnotetext{
ii The exhibition was first presented at the Arc en Reve Centre d'Architecture in Bordeaux in 1994, then at the Centre Georges Pompidou in Paris and subsequently travelled to numerous museum and galleries around the world as an itinerant architectural witness of the destruction.

iii ‘'The 'Oriental period, Oriental influences until 1878', 'The 'Austro-Hungarian period, European influences until 1918', 'The 'period between the two wars, Modern period until 1941 ', 'The post war period, contemporary architecture, until 1992'.

" In the dossier's introduction the authors write: " $[\mathrm{T}]$ he aggressor perpetrated a planned cultural genocide and urbicide, systematically destroying all aspects of urban life which symbolized our coexisting communities....' Association of Architects DAS-SABIH
} 
Sarajevo (1994).

vii The explosive and instantaneous theoretical provocation of the Fireworks was enacted again in 1992, with their display in the Tschumi-designed Parc de la Villette in Paris, and in 2009 at the Architectural Association in London.

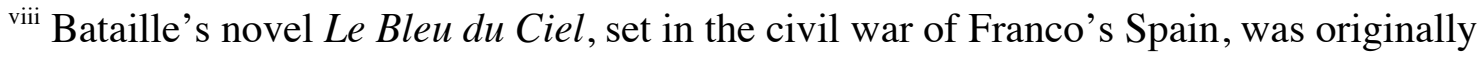
published in 1935.

xiii I have analyzed this case and some of the reactions to Libeskind's project in Stoppani, 2006.

${ }^{x v}$ See for example Karlheinz Stockhausen's controversial and contested declaration that the attack constituted "the greatest work of art imaginable" (in Sorkin, 2003, p. 17). 